\title{
Strategies for Managing Stress for Optimal Job Performance
}

\author{
Olorunsola Henry Kofoworola ${ }^{1} \&$ Ajibua Michael Alayode ${ }^{2}$ \\ ${ }^{1}$ Department of Physical and Health Education, Obafemi Awolowo University, Ile-Ife, Nigeria \\ ${ }^{2}$ Sports Center, Federal University of Technology, Akure, Nigeria \\ Correspondence: Ajibua Michael Alayode, Sports Centre, Federal University of Technology, Akure, Ondo State, \\ 234-34, Nigeria. Tel: 234-80-3814-2303. E-mail: alayodeajibua@gmail.com
}

Received: February 10, 2012 Accepted: March 19, $2012 \quad$ Published: June 1, 2012

doi:10.5539/ijps.v4n2p162 URL: http://dx.doi.org/10.5539/ijps.v4n2p162

\begin{abstract}
Studies have shown that stress is an inevitable part of life. It is the inability of individual to cope with threat (real or imagined) which results in series of responses and adaptations. It can lead to feelings of depression, frustration and anxiety. As much as the physical effects of this 'epidemic' are often emphasized, the economic consequences are also alarming. It has been discovered that not all stress are bad, some are actually needed to move forward in life. Thus, stress can be seen as a friend and foe; it is found among the rich and the poor. The purpose of this paper is to discuss the concept of stress and its causes, how to identify the signs and symptoms and the strategies for eliminating it.
\end{abstract}

Keywords: eustress, epidemics, psychosomatics, hyperactivity, mood swinging, phobia, religion coping

\section{Introduction}

Stress has been defined as a "global epidemic" by United Nations International Labour Organization. As much as the physical effects of this epidemic are often emphasized, the economic consequences are also alarming. In the United Nations' report of 1993, stress at work is described as "XX century disease" (Mihailovic (2005). Excessive burden of mental system caused by stress affects productivity, quality of work done, process of it, number of mistakes made, and the number of injuries at work. Workplace stress cost United States of America's employers an estimated $\$ 200$ billion per year in absenteeism, low productivity, staff turnover, workers' compensation, medical insurance and other stress related expenses (Maxon, 1999). Considering this, stress management may be businesses' most important challenge of the $21^{\text {st }}$ century.

Stress is an inevitable part of life (Oloyede and Akinbile, 2010). It can lead to feelings of frustration, depression and anxiety. Stress can take a toll both physically and emotionally, causing psychosomatic illness (Ola, 2008). The term "psychosomatic" is coined from the Greek words "psycho" which means "mind", and "soma" which means "body". Psychosomatic illness results from the influence of the mind on the body. No matter what the adverse effects of stress may be, it is part of life. An unwritten law of life is that it is friction that produces stretching which brings about enhanced performance in life (Afeniforo, 2006). This position agrees with that of Ademola (2005) who maintains that human lives are filled with pressures and problems. According to him, these problems and pressures can produce either positive or negative results depending on the biological and psychological make-up of individuals. Stress is a self-induced action that develops as soon as one notices problems. It is, therefore, important to always anticipate problem and device ways of solving them before they come. Many people hold the opinion that only the "big men" are susceptible to tension and stress. This is a wrong belief because several factors could set stress in motion in one's life (Ola, 2008). The purpose of this paper is to discuss the concept of stress, causes, signs and symptoms and strategies for managing it. Understanding all these will assist employees and organizations to adopt preventive mechanisms against stress.

\section{Concept of Stress}

Ademola (2005) described stress as the inability to cope with threat (real or imagined) which results in series of responses and adaptations. Melinda, Ellen and Jeanne (2010) remarked that it is the emotional and physical strain caused by our responses to pressures from the outside world. Common stress reactions according to them include tension, irritability and inability to concentrate. In the opinion of Morgolis, Kroses and Hurrel (1975) stress is non-specific biological, emotional and behavioural process that occurs when physical or psychological well-being is disrupted or threatened. Ola (2008) cites stress as nervous tension that results from internal 
conflicts from a wide range of external situations. It can simply be put as wears and tears within the body that results from responses to external situations. Stress is an anxious reaction of people to what happens to them or what they fear might happen. It can also be viewed as the condition or feeling in which one is when one believes that demands in one's life exceed personal and social means which one has at one's disposal.

Morgolis et al, (1974) reported that in 1959, a Doctor Hans Selye began with the first explanation of stress. His work started from the developmental phenomenon of stress and its consequences. He noted that in each reaction to stress, three phases could be detected,

- Phase of panic reaction or alarm stage;

- Phase of resistance or resistance stage; and

- Phase of exhaustion or exhaustion stage.

These are referred to as General Adaptation Syndrome (GAS). The phase of panic reaction is the starting phase, which does not last long and in which the body is preparing itself for a stressful situation by recuperating. During the phase of resistance, the body starts fighting stress and tries to adapt to it. If the pressure weakens, it means that the personality is overcoming stress. If the stress lasts, a long and tormenting adaptation takes place, which can have a lot of unwanted consequences. Finally, the phase of exhaustion sets in if the mechanisms of adaptation fail. The phenomenon of adaptation is a sign that the body has used up all its defense and is exhausted. Fletcher and Scott (2010) study reveals that a long fight with stress can lead to stress diseases.

\subsection{Stress as a Friend}

Research indicates that not all stress is bad (Melinda, Ellen, and Jeanne, 2010 and Baqutayan, 2011). The "friendly" stress is called Eustress. It is a short term stress that provides immediate strength. It rises at the point of increased physical activity, enthusiasm and creativity. Eustress is a positive stress that arises when motivation and inspiration are needed (Asagba and Atare, 2010). It prepares the bones, muscles, tendons and senses to carry out extra exertion without being strained. This type of stress is what comes to play when preparing for competitions and interviews. According to Maxon (1999), no one reaches peak performance whether, an athlete, an office worker or a manager without it.

\subsection{Stress as a Foe}

The bad stress is referred to as distress (Jeanne, Melinda, Lawrence, 2010). This is a negative stress brought about by constant readjustment or alteration in a routine. Distress creates feelings of discomfort and unfamiliarity. Large amounts of adrenalin are produced during distress. This puts the body in overdrive, burning loads of calories needed to run the nervous system. Blood sugar as well as glycogen reserves are depleted during distress. During distress there is an increase in aggression, anxiety, rage and other strong emotions. These emotions are fine if tempered and directed positively. However, if uncontrolled they can lead to inappropriate and destructive behaviors. It can also lead to very serious chronic illness (Satovic, 2005).

\section{Causes of Stress in Work-place}

Stress occurs under certain circumstances; these include life changes, hassles, goal-setting, workload, role conflicts, career development, children/family pressures, relationship difficulties, inability to accept uncertainty, unrealistic expectation, negative self-talk, etc (Margolis, Kroes and Hurrel, 1974).

\subsection{Life Changed}

In our today's society, a number of events that people consider to be positive, including marriage, retirements, pregnancy, outstanding personality and achievement may cause stress (Asagba and Atare, 2010).

\subsection{Hassles}

These are frustrating everyday situations and events that interfere with ability to function effectively or to attain goals. Experience has shown that daily hassles contribute a significant amount to overall stress. An example is public servants looking for lost files, replacing crashed diskette, and how to answer query from superior officers.

\subsection{Job Stress}

Stress varies from one occupation to another. It appears that the most single factor that may likely lead to job stress is poor fit between an individual and the job environment (Margolis, Kroes and Hurrel, 1974). If one has inadequate talent or training for his job, it is expected that the output will be low and this may lead to stress.

\subsection{Career Development}

Several career issues can act as a source of stress. These may include job insecurity, over-promotion, 
under-promotion etc. In Nigeria, society places a great deal of emphasis on achievement and ability to succeed in all aspect of life. Due to inability to meet expectation an individual may become stressed.

\subsection{Workload}

Because of economic downturn many governments all over the world are reducing employment opportunities for their citizenry. Most times, workers are made to do more than what they are to do under a normal situation.

\subsection{Insecurity}

The level of insecurity in Nigeria today is very high. The emerging of different militant groups such as the Odua Peoples' Congress, Arewa Peoples' Congress, Egbesu Boys, the Bakkasi Boys has made life difficult for the people of Nigeria. Recently a terrorist group called Boko Haram has continued to use suicide bombers to bomb churches and markets. People know leave in perpetual fear.

\section{Signs and Symptom of Stress}

The signs and symptoms of stress according to Asagba \& Atare, (2010), Ademola (2005 \& 2010), and Melinda et al (2010) can be categorized into four groups, i.e., cognitive, physical, emotional and behavioural.

\subsection{Physical Signs and Symptoms}

Physical illness can be caused by non-physical problems, so it is important to have a medical doctor treat conditions such as ulcers, compressed disks, or other physical disorders. The physical problems listed below may result from stress.

- Aches and pains

- Diarrhea or constipation

- Nausea and dizziness

- Chest pain and rapid heart beats

- Loss of sex drive

- Frequent colds

- Sweaty palms

- Weight gain or loss

- Weakness

- Tiredness and chronic fatigue

- Breathlessness

- Hyperactivity

- Muscular tension

- Teeth grinding or jaw clenching; etc

\subsection{Cognitive Signs and Symptom}

Stress may also affect the mental gamut of individuals in the following ways:

- Memory problems

- Inability to concentrate

- Poor judgment

- Seeing only the negative

- Anxiety

- Constant worry

- Fearful anticipation

- Loss of objectivity; etc.

4.3 Emotional Signs and Symptoms

The under-listed emotional symptoms can make someone uncomfortable and can affect one's performance at work or during play activities.

- Mood swinging 
- Irritability,

- frustration

- "Butterflies"

- Agitation

- Feeling of overwhelm

- Sense of loneliness and isolation

- Depression

- Anger and resentment

- Inability to relax

- Feeling tensed and on edge

- Substance abuse

- Phobias

\subsection{Behavioural Symptoms}

The antisocial behavior display in stressful situations can cause rapid deterioration of relationships with family, friends, co-workers or even strangers. Some of which are:

- Eating disorder

- Sleeping too much or too little

- Procrastination or neglecting responsibilities

- Increased arguments

- Domestic or workplace violence

- Overreaction

\section{Strategies for Managing Stress}

Stress control is key to successful career. Psychologists have identified two ways in which people cope with stress. In the first approach, a person may decide to suffer or deny the experience of stress. Alternatively, one may decide to face the realities and proffer solutions to it (Pestogee, 1992). Instead of taking stimuli and tranquilizers to eliminate stress, people should learn other better ways of avoiding stress and diminishing its damaging effects. The following methods have proved to be efficient for eliminating stress:

\subsection{Mental Training}

Mental training is the use of the "mind's eye" in a range of psychological techniques designed to induce relaxation and increase confidence (Jarvis, 2000 and Onifade, 2005). It refers to all those quasi-sensory and quasi-perceptual experiences of which we are self-consciously aware of and which exists for us in the absence of those stimulus conditions that are known to produce their genuine sensory or perceptual counterparts (Richardson, 1985). It may include techniques such as mental imagery, visualization etc. By this method, people can be trained on how to mentally overcome a stressful situations and not how to avoid them, considering the fact that in many professions, it is impossible to do so because of the nature of work.

\subsection{Physical Activity}

Aderinola (2011) remarked that human body is designed to move-just like those of automobiles and if they don't move, they become stiff and rusty. Studies designed to examine the actual psychological buffering mechanisms linking leisure physical activities indicated that participation in physical activities has the capacity to reduce stress (Coleman, 1993). As well, people whose physical activity involvement enhanced friendship networks and enjoyment of activities were found to report less depression and fewer physical depression and fewer physical symptoms when under stress (Iso-Ahola and Parks, 1996).

Participation in physical activities stimulates the discharge of matter that work as natural anti-depressive-noradrenalin, endorphin and encephalin. It can greatly reduce stress and degree of reaction to it (Public Library of science, 2010). Several studies support the fact that comprehensive work-based leisure-time activities can yield promising health behavior changes (NASPE, 2003 and Ericksen \& Brunsgaard, 2004). A study has found that taking long walks can be effective at reducing anxiety and blood pressure (Smith, 2002), while another study indicates that brisk walk of as little as 20 minutes duration can leave people feeling more 
relaxed, refreshed and energetic for up to two hours (Ericksen and Brunsgaard, 2004). Other recent findings reveal the potential of participation in physical exercises to contribute to positive health not merely the absence of diseases but associated with the capacity to enhance life satisfaction and ability to improve individual's capacity to withstand stress (Barcelona, 2002; Gautam, Sarto \& Kai, 2007 and Harworth, 2008).

\subsection{Writing}

Research has shown that writing about stressful situations can help overcome stress and enhance quick recovery from illness caused by stressful situations. 10-15 minutes of writing per day is recommended, as one can transfer one's feelings and emotions during stressful situations on papers (Horwitz, Ellen, Melinda, 2010).

\subsection{Discussion}

By expressing one's thoughts and sharing them with family members and friends, one can better understand one's feelings (Fletcher and Scott, 2010). Discussion about observations, thoughts and reactions toward stressors and trauma is of great importance (Pestonjee, 1992).

\subsection{Rest and Relaxation}

All living things have a rhythm of activity and rest and human beings are not exception to this natural law. Aderinola (2011) opined that without rest, the body is at a disadvantage and is less able to conserve its good health and resist diseases, and if the body should develop an illness, the healing process is more difficult or simply does not take place at all.

It is important to retain and ensure sleep rhythm which provides enough sleep and time to relax. Sleep provides a number of important psychological and physiological functions (Beersna, 1998). Frank (2006) suggested several possible perspectives on sleep function. The first, a somatic theory of function, highlighting the restorative relationship between sleep and the immune and endocrine systems. The second theory is a neuro-metabolic one, proposing that waking imposes a neural and metabolic cost that is "paid" for via subsequent sleep. This includes both detoxification and restoration of the nervous system. The final theory (cognitive theory) suggests that sleep plays a vital role in learning, memory and synaptic plasticity.

According to Aderinola (2011) listed the contributions of rest and relaxation as follow:

(i) It allows the body to renew itself. Waste products are removed, repaired are effected, enzymes are replenished, energy is restored

(ii) It aids in the healing of injuries, infections and other assaults on human body, including stress and emotional traumas

(iii) It strengthens human body immunes system, helping protect one from disease.

(iv) It can increase longevity. People who regularly sleep seven to eight hours each night will have lower death rates that those whose average either less than seven hours

\subsection{Diet}

The performance of individuals in human endeavour rests solely on what they eat (Famayo and Adubi, 2008). Thus, it is very important to eat regularly to avoid ill-health. The type of food and the time they are consumed or eaten them are very important. If a person intends to have good health, his/her meal should be regularly timed and distanced. There is much importance to be attached to the kind of food we take (Johnson, 2006), but the time of consuming the food, has a much more important bearing on human health (Morgan, 1972). Dietary factors which may improve sleep and stress include eating a balance diet containing vegetables, grains and consuming B- vitamin, iron, magnesium, zinc, calcium and copper.

\subsection{Reduced Commitments}

For many years there has been extensive research on organizational commitment since there was a strong belief that commitment has relevant importance for both the organization and employees. For organizations, organizational commitment is believed to have significant relationship with performance, reduced turnover and absenteeism rate which will in turn contribute to productivity growth (Omolara, 2008 and Ahmad, Amin and Ismail, 2010).

From employees perspective, being committed to one's job and organization represents a positive relationship that would potentially add more meaning to life, for instance, increase in self-worth and satisfaction (Maxon, 1999). However, excessive commitments, whether it is overtime at work, working on several projects at a time, or other working activity often creates anxiety and tension (Draker, 2005). It is therefore very important that activities are prioritized to avoid stressful situations. Strategic management experts are of the opinion that time 
management can do much in reducing stress.

\subsection{Professional Help}

Stress can be difficult and discouraging if the situation is not controlled. The best thing to do is to ask for professional assistance. Getting professional assistance will help to reduce the symptoms and total reduction of everyday stress (Mihaukovic, 2005).

\subsection{Develop a Heart of Gratitude}

We must always acknowledge who we are, what we are and express gratitude for it so that the universe can give us all that we want and need. Gratitude is a powerful tool that helps one break down the wall of resistance. It can be used as a transformational tool that will shift emotional state and increase self-esteem. As one appreciates life from the heart, the more the magnetic energy of appreciation attracts fulfilling life experiences to one (Paddisson, 2010).

\subsection{Religion Orientation}

Pargament (1998) emphasized that religion can be used as a buffering process to reduce the level of stress and strain at work. He gave three roles of religion in the coping process. Religion can serve (i) as part of elements of coping, (ii) as contributor to coping, (iii) as product of coping. Higher order factor analyses have revealed that positive religious coping strategies which reflect confidence and self-esteem can turn religion to a coping support for people undergoing stressful life events (Pargament, 1998; Ano and Vasconcelles, 2005).

\section{Conclusion}

Reviews on the earlier research findings indicate that workplace stress constitute a major nuisance to economic growth and development. Thus, knowing the causes of stress, its signs and symptoms and the strategies for eliminating it, will help employees and organizations to take appropriate steps to alleviate stress experience. By this, organizations will not only have satisfied, committed and productive workers, but also reduce cost related to stress.

\section{References}

Ademola, A. (2005). Performance under stress: What the coaches should do. A paper delivered at the seminar on mental skill training in sport organized by National Institute for Sport, Lagos.

Ademola, A. (2010). The role of physical activity and exercise in the management of work stress (pp.139-148). A book of reading in honour of Professor Veroniocal C. Igbanugo, Department of Human Kinetics and Health Education, University of Ibadan.

Aderinola E. A. (April, 2011). Health: By choice; not by chance. A Public lecture on "Healthy Living" presented to Federal University of Technology, Akure Community in Ondo State, Nigeria.

Ahmad, U. N. U., Amin, S. M., \& Ismail W. K. W. (2010). Technostress and organizational commitment: A proposed framework. The Journal of the Malaysian Institute of Management.

Ano, G. G., \& Vasconcelles, E. B. (2005). Religious coping and psychological adjustment in stress: A meta-analysis, J. Clin. Psychol, 61, 1-20. http://dx.doi.org/10.1002/jclp.20049

Asagba, B. O., \& Atare, U. (2010). Exercises in stress management (pp. 401-407). A book of reading in honour of Professor Veronica C. Igbanugo, Department of Human Kinetics and Health Education, University of Ibadan.

Baqutayan, S. M. S. (2011). The Importance of religion orientation in managing stress. International Journal of Psychological Studies, 3(1).

Beersna, D. G. (1998). Models of human sleep regulation. Sleep Medicine Reviews, 2, 31-43. http://dx.doi.org/10.1016/S1087-0792(98)90052-1

Coleman, D. (1993). Leisure based support, leisure disposition and health. Journal of Leisure Research, 25, 350-361.

Draker, J. (2006). Vestina devotvornog direktora. Novi Sad: Graph Style.

Dunham, J. (1992). Stress in teaching. London: Routhledge. http://dx.doi.org/10.4324/9780203314500

Ericksen, W., \& Brunsgaard R. (2004). Do physical leisure time activities prevent fatigue. A 15-month prospective study of nurses aids. British Journal of Sports Medicine, 38, 331-336. http://dx.doi.org/10.1136/bjsm.2002.004390 
Fletcher, D., \& Scott, M. (2010). Psychological stress in sport coaching: A review of concept, research and practice. Journal of Sport Sciences, 28(2), 127-137. http://dx.doi.org/10.1080/02640410903406208

Famayo M. O., \& Adubi. (2008). Relationship between good nutritional standard and athletes performances in sport competition. Journal of Physical Education and Research, 13(1), 1912-1919.

Frank M. G. (2006). The mystery of sleep function: Current perspectives and future directions. Reviews in Neurosciences, 17, 375-392.

Gautam, R. Sarto, T., \& Kai. I. (2007). Public Health. Retrieved from http://www.biomedicentral. com

Halson, S. L. (2008). Nutirtion, sleep, and recovery. European Journal of sport science, 8(2), 119-126. http://dx.doi.org/10.1080/17461390801954794

Harworth, J. (2008). Work, Leisure and Well-being. Economic and Social Research Council and Manchester Metropolitan University.

Horwitz, L., Ellen J. M. A., Melinda, S. M. A., \& Roberts S. M. A. (2010). How to reduce and manage job and workplace stress. Retrieved from http://www.helpguide.org

Iso-Ahola, S. E., \& Park J. K. (1996). Leisure-related social support and self-determination as buffer to stress-illness relationship. Journal of Leisure Research, 28,169-189

Jarvis, M. (2000). Sport psychology. London, Routhledge Publishers.

Jeanne, S., Melinda S. M. A., \& Lawrence, R. (2010). Fast and effective ways to rapidly reduce stress. Retrieved from http://www.helpguide.org

Johnson, M. (2006). Nutrition. Graduate Student Reviewer, University of Minnesota.

Maxon, R. (1999). Stress in the workplace: A costly epidemic. Fairleigh Dickinson University publication.

Melinda S. M. A., Ellen J. M. A., \& Jeanne, S. (2010). Understanding stress. Retrieved from http://www.helpguide.org.

Mihankovic, D. (2005). Psihologija u organizaciji. Beograd: Fakultet organizacionnih nauka.

Morgan, W. P. (1972). Ergogenic Aids and Muscular Performance. New York.

NASPE. (2003). How Teens and Adults feel About Physical Activity \& Education: A Survey Concluded for NASPE. The Sport Journal, 6(2).

Ola S. P. (2008). Goal setting: A practical approach (pp. 115-127). Akure, Golden Prince Nig. Ltd.

Oloyede, R. O., \& Akinbile, P. O. (2010). Management of stress at work among Adeyemi College of Education staff (pp. 401-407). A book of reading in honour of Professor Veronica C. Igbanugo, Dept of Human Kinetics and Health Education. University of Ibadan.

Omolara, B. E. (2008). Influence of workplace stress on organizational commitment at Olabisi Onabanjo University Ago-Iwoye, Ogun State Nigeria. Paper presented at the 2008 EABR \& TLC Conference Proceedings, Rothenburg, Germany.

Onifade A. (2005). Mental imagery for performance enhancement in sports. A paper delivered at the seminar on mental skill training in sport organized by National Institute for Sport, Lagos.

Paddison, S. (2010). The hidden power of heart: Discovering an unlimited source of intelligence. Christmas lecture synopsis.

Pargament, K. L. (1997). The psychology of religion and coping: theory, research and practices. Guidhall Press, London.

Pestonjee, D. M. (1992). Stress and coping. New Delhi: sage.

Satovic, A. (2005). Stres na radman mjestu. Tuzla: psitijatrijska klinika, UKC Tuzla, Medicinskitakultet U Tuzli.

Smith J. C. (2002). Stress Management: A comprehensive handbook of techniques and strategies. New York: Springer. 